\title{
Rheumatic heart disease: prevalence and preventive measures in the Indian subcontinent
}

Although once considered a rarity in the Indian subcontinent, the prevalence of rheumatic heart disease (RHD) is now recognised to be very high, particularly among children and young adults. ${ }^{1}$ Indeed, such was the severity of the problem in developing countries that in 1982 the World Health Organization/International Society and Federation of Cardiology established a committee to combat the disease over a phased period. As a result, the prevalence of RHD has subsided in certain countries in the Middle East, and in Thailand. ${ }^{2}$

In contrast to previous sources of data upon which to base the prevalence of RHD (for example, necropsies, general population surveys, insurance data $^{3}$ ), prevalence figures over the past five years have been derived almost entirely from school surveys. Between 1940 and 1983, the prevalence rate for RHD varied from 1.8 to 11 per 1000 (national average 6 per 1000), while between 1984 and 1995 the rate varied from 1 to 5.4 per 1000 . During the same periods of time, the prevalence of rheumatic fever ranged from 0.06 to 5.01 and 0.32 to 0.54 per 1000 , respectively. Because of the different methods of collecting the data it is not possible to be certain that these figures represent a fall in the prevalence of RHD. By comparison, in western countries the prevalence of RHD in children aged between $5-15$ years is below 0.5 per $1000,{ }^{4}$ and for rheumatic fever it is below 1 per 1000 .

\section{Age and sex incidence}

Several recent studies conducted in India have further highlighted the unacceptably high prevalence of RHD among children and adolescents, ${ }^{5-8}$ and in patients undergoing balloon mitral valvotomy for juvenile mitral stenosis. Girls and women in particular seem to be severely affected, possibly as a result of being housebound and having to live in overcrowded conditions. Overpopulation, overcrowding, poverty, and poor access to medical care are undoubtedly the main reasons for the high prevalence of RHD in India.

Another reason may be the inadequate use of penicillin by general practitioners because of fears over allergic reactions. Although penicillin remains the drug of choice for RHD and rheumatic fever, ${ }^{2}$ in some Indian states there are government orders prohibiting penicillin injections in hospitals. Fortunately, fears over penicillin allergy are gradually being allayed.

As for the situation in other countries in the Indian subcontinent, there are no recent data available for Pakistan, Sri Lanka, Bangladesh, and Bhutan. However, a recent study in Nepal reported a prevalence of 1.2 per 1000 in an isolated school survey involving 4736 pupils. $^{9}$
The recent introduction of balloon mitral valvotomy is proving popular in India, as it is much less expensive to carry out and does not result in a chest scar (which carries a stigma in Indian society). In addition, catheters such as the Inoue balloon can be reused several times, further helping to reduce costs..$^{10} 11$

The Indian Council of Medical Research has identified two levels of health care services for controlling and preventing RHD-primary health centres, and school health services. These services employ secondary and, to a lesser extent, primary prophylactic measures. However, a lack of political will and financial constraints-coupled with competition for funds from the large number of adult cardiac cases caused by the upsurge in coronary heart disease - have prevented these prophylactic measures from being widely implemented. However, awareness about the importance of RHD and how this disease can be prevented has increased considerably throughout the country. There is also the prospect of a vaccine for rheumatic fever becoming available. Trials of this vaccine are underway, ${ }^{12}$ including two in India. Should these trials prove successful, the disease that kills so many children and young adults could one day be eradicated from the subcontinent.

National Heart Institute,

S PADMAVATI

49 Community Centre,

East of Kailash,

New Delhi 110065,

India

1 Padmavati S. Rheumatic fever and rheumatic heart disease in developing countries. Bull World Health Organ 1978;56:543.

2 World Health Organization. Rheumatic fever and rheumatic heart disease. Geneva: WHO, 1988, TRS-764.

3 Padmavati S. Rheumatic fever and rheumatic heart disease in India. In: Yu PN, ed. Progress in cardiology. Philadelphia; Lea \& Febiger, 1987:169-83

4 Padmavati S. Present status of rheumatic fever and rheumatic heart disease in India. Indian Heart $\mathcal{F}$ 1995;47:395-8.

5 Sharma M, Saxena A, Kothari SS, et al. Acute rheumatic fever in children: experience from a cardiac centre [abstract]. Indian Heart f 1999;51:652.

Mishra TK, Rath PK, Mohanty NK, et al. Juvenile chronic RHD: our decMishra TK, Rath PK, Mohanty NK, et al. Juvenile chronic RH.
ade long experience [abstract]. Indian Heart f 1999;51:653.

7 Ahamed MZ, Jayasree P, Narayanan SN. Rheumatic chorea in children-a study of prevalence of clinical and echocardiographic valvular involvement [abstract]. Indian Heart f 1999;51:694.

8 Cardiological Society of India. Non-coronary cardiac interventions. Second report by the non-coronary cardiac interventions registry of India. Cardiological Society of India, 1997.

9 Regmi PR, Pandey MR. Rheumatic fever and rheumatic heart disease in school children of Kathmandu city. Indian Heart f 1997;49:518-20.

10 Cardiological Society of India. Reuse of disposables in the catheterisation laboratory - report of the committee appointed by the Cardiological Society of India. Indian Heart $\mathcal{F}$ 1997;49:329-31.

11 Vlietstra RE. Interventional cardiology worldwide. F Intervent Cardiol 1995; 8:17-18.

12 Pruksakorn S, Currie B, Brandt E, et al. Vaccine for rheumatic fever. Lancet 1994;344:639-42. 